SALES DE LA CRUZ, Mònica: Quan les revistes conten rondalles. Barcelona: Publicacions de l'Abadia de Montserrat, 20I6, I76 p.

\title{
Quan les revistes conten rondalles
}

M. Jesús FrancÉs Mira

Universitat d'Alacant

La professora de la Universitat Rovira i Virgili (Tarragona) i estudiosa del folklore i l'etnopoètica, Mònica Sales, ha demostrat en un treball minuciós dividit en huit parts la importància d'aquesta matèria en les publicacions periòdiques catalanes del segle XIX, coincidint amb el moviment de la Renaixença que impulsa aquests interessos. Fet el buidatge bibliogràfic necessari per l'estudiosa i d'altres investigadors universitaris, abocat a la base de dades del projecte «Repertori Bibliogràfic de literatura popular catalana: el cicle romàntic» (RBLPC), es va haver d'acotar el corpus de treball al gènere de la rondalla en 28 revistes catalanes publicades al segle XIX (460 mostres que després han estat reduïdes per no complir totes amb els paràmetres de la rondalla com a tal). Sales explica que el fet d'escollir aquest gènere ha estat per continuar amb la tasca encetada pels estudiosos Carme Oriol i Josep M. Pujol en aquesta via que ha desembocat en el portal informàtic RondCat: Cercador de la rondalla catalana <http://rondcat.arxiudefolklore.cat $>$. L'ampliació, doncs, d'aquest portal per l'estudiosa ve per la via de l'anàlisi de dos tipus de rondalles: aquelles que estan catalogades amb l'índex internacional i que reben un número ATU (The Types of International Folktales, Uther 2004) i aquelles que no ho estan, amb la finalitat d'«observar quin tipus de rondalles tenien més interès (d'animals, meravelloses, religioses, de gegant beneit o contarelles), quins arguments eren els més difosos, quina funció tenien i també quins estudiosos les recollien i les publicaven i en quines revistes» (p. I6).

Per cloure el primer dels apartats, Sales fa un inventari de les fonts consultades en general per al projecte RBLPC, que ascendeixen a un total de 35 revistes (compreses en les dates seleccionades: del I823 al I893), de les quals 66 són les que han estat més vàlides per a la investigació i que arriben des de les diferents contrades catalanoparlants, així com d'altres. L'estudiosa també aporta les dades d'aquelles 74 revistes que no han format part del procés per no ajustar-se al que demanava l'esmentat projecte d'on naix i beu el present estudi.

La segona part del treball, tal com diu el títol «El folklore a Catalunya durant el segle XIx: una panoràmica», ajuda a entendre que en aquest segle es desperte un gran interès pel folklore en tot Europa, que va lligat al moviment del Romanticisme, després d'un segle XVIII que unia la cultura tradicional a un fort sentiment nacionalista. Aquest Romanticisme abocava sobre les esquenes del poble —entès com a rural- l'essència popular que es volia transmetre, però l'estudiosa sap «desmitificar el prejudici ruralista» (p. 28) mitjançant l'estudi de testimonis apareguts en la premsa del segle xix, en què hi ha una doble via de recollida de material que denomina directa i indirecta: tal com exemplifica, o bé hi ha un transvasament d'informació de l'informant al recol-lector, o bé la informació arriba mitjançant material escrit de col-laboradors cultes. Arran d'açò, la investigadora trau a la llum la fidelitat o no dels investigadors d'allò que el poble ha testimoniat, amb defensors com Cel Gomis en contra d'altres detractors. 
L'interès per la literatura oral a Catalunya s'implanta amb l'adaptació del Romanticisme en aquest territori, és a dir, amb la Renaixença, que busca l'essència del catalanisme mitjançant símbols que van des del món rural i pagès a la llengua, com els més destacats i lligats entre si. Tornem a la idea que la identitat nacional més pura es troba a través de la llengua en aquest context rural, propi de la concepció del folklore al segle XIX que progressivament anirà evolucionant. Els materials amb més suc seran les llegendes i les rondalles, tot i el primer interès dels estudiosos per les cançons, i es donaran a conèixer o bé per la via tradicional de les entrevistes directes o bé a través de cartes. Així, l'objectiu primer de «fer pàtria» amb aquesta recerca passarà a ser «matèria d'estudi» com a tal, i aniran formant-se al seu voltant generacions d'estudiosos. Sales va parlant-ne de tres, entre les quals la intervenció de Francesc Maspons i Labrós serà de gran rellevància. El canvi al-ludit es comprova quan la tercera generació veu necessari seguir un mètode d'estudi que marca un caràcter més rigorós de la matèria i ací entra en joc un altre canvi: la recerca individual per la col-lectiva mitjançant les associacions excursionistes que, com l'Associació d'Excursions Catalana, publica en el seu Butlletí, tal com il-lustra l'estudiosa, una circular amb una guia d'interrogatori que puguen seguir els membres que arrepleguen folklore per Catalunya. Els butlletins i, per tant, la premsa periòdica que difon la diversitat de literatura oral existent augmenta i així continuarà a les mans dels noucentistes.

L'autora continua el seu viatge d'indagació, ara centrant-se en la presència, la difusió i el contingut de la premsa catalana del segle xix. Aquesta resulta ser molt nombrosa alhora que molt diversa pel que fa a temàtiques i es classifica en dos grups: revistes generals i revistes específiques, tant pel que fa al contingut com a l'àmbit d'expansió. L'estudiosa afirma que encara que no hi havia revistes centrades en el folklore i l'etnopoètica, era notable la inclusió d'aquests materials en les diferents publicacions al costat d'altres temes, unes publicacions amb gran acceptació del públic lector. El progrés d'aquesta matèria fa que no només hi apareguen mostres de tradició oral, sinó també reflexions sobre aquest progrés. La premsa del moment, a més, es fa eco del pas de la recerca individual a la col-lectiva mitjançant l'associacionisme, concretament a través de les associacions excursionistes, que combreguen amb la creació de seccions específiques per al folklore dins dels seus butlletins - per exemple «al Butlletí Mensual de l'Associació d'Excursions Catalana, la 'Secció de Folklore Català'» (p. 53).

Fent honor a un sentit de la divulgació didàctic, la investigadora mostra, prèvia explicació, una taula on sistematitza i cataloga les I5 revistes d'on ha pogut extraure les I27 rondalles amb què treballa, de les 28 revistes utilitzades en un primer moment per al present estudi (I3 se n'han descartat per no contindre mostres d'aquest gènere). Davant la gran quantitat de materials propis de la literatura oral arreplegats en les diferents revistes buidades per al projecte RBLPC mencionat adés, l'autora, membre d'aquest, es veu en el deure de mostrar succintament quins són aquests materials amb l'aportació primera de l'article que l'erudit Cels Gomis publicà l'any i884 en L'Avens per endinsar-se en la difícil tasca de sistematitzar la literatura oral del moment (una tasca que, com bé adverteix Sales, ja ha estat superada, però que s'ajusta a l'època matèria d'estudi). Aquesta tasca li serveix a l'autora per fer veure la classificació tan simple del gènere que li preocupa: una divisió a tres entre rondalles meravelloses, morals i per riure; també li serveix 
per remarcar les paraules de Gomis respecte a les dificultats que els recol-lectors poden trobar-se a causa de les desconfiances que es desperten, minvades per l'accessibilitat que mostren les dones més grans, així com li serveix per parlar de les adaptacions terminològiques necessàries que s'hi han hagut de fer des d'aquell segle xix a l'actualitat.

Fetes aquestes reflexions, l'estudiosa comença a esmicolar els diferents gèneres, definint-los quan considera convenient o bé especificant-ne els tipus, així com la seua presència en la premsa catalana del segle XIX, de manera que fa un recorregut per l'acudit, la cançó, la contarella, l'enigma, la llegenda, el mimologisme, la parèmia, el relat etiològic, la rondalla i la tradició. I s'hi remarca una idea: riquesa de revistes i de materials.

L'obtenció d'aquests materials suposa una tasca prèvia dels recol-lectors, un grup heterogeni quant a professions que, com bé destaca l'autora, demostra l'interès social per aquest "patrimoni immaterial». Per aquesta raó, hi ha una panoràmica d'aquest col-lectiu a partir de la dècada dels cinquanta del segle XIx, un col-lectiu que ja en la dècada dels seixanta augmenta l'aportació que fa a la premsa catalana del moment, fet que anirà in crescendo; que va augmentant en nombre en relació amb l'aparició de les societats excursionistes; que es caracteritza per ser autodidacta, i que pot jugar o no amb la seua identitat depenent de si utilitzen nom complet, sigles, pseudònims o el silenci. La panoràmica que esmentàvem després, Sales la concreta amb un repàs ara ja més centrat en les aportacions de rondalles en revistes que fan els diferents recol-lectors a partir de l'anàlisi de les diferents dècades des de la del cinquanta fins a arribar a la data límit establerta, el I893. Un repàs, aquest, sistematitzat en una taula que tanca aquest apartat novament amb una visió més clara d'allò exposat: hi ha els noms dels recol-lectors, les rondalles aportades, la dècada en què ho han fet i la professió que desenvolupen. Així es mostra l'interès per aquest material d'un grup ben heterogeni, com dèiem, quant a oficis, i es destaquen noms com els de Manuel Milà i Fontanals o Francesc de Sales Maspons i Labrós.

Els apartats cinquè i sisè del present estudi formen un tàndem, ja que el primer pretén, sobretot, contextualitzar la rondalla pel que fa a l'època estudiada, amb l'especificació de quines rondalles entren en aquest estudi vertebrades en tres branques: rondalles catalogades en l'índex internacional, rondalles no catalogades i rondalles catalogades en el RondCat. El segon apartat del tàndem presenta un tast d'aquestes rondalles amb la selecció de la primera de cada apartat, de manera que es mostra l'estructura que presenta i els paràmetres, especialment pel que fa a la transcripció.

Quant a la contextualització del primer d'aquests dos apartats del tàndem, Sales recorda noms tan importants per a la rondalla com els germans Grimm, fidels a l'oralitat, precedits per les remodelacions que feia Perrault i seguits per la influència de Hans Christian Andersen com a imitador de les rondalles tradicionals. Així mateix, recorda les teories que buscaven l'origen mateix de la rondalla, on es remarca la transcendència de la teoria historicogeogràfica per la funcionalitat dels catàlegs tipològics que emprava. Açò du a l'estudiosa a parlar de la difícil definició del terme rondalla i a explicar els diferents subgèneres que engloba, des de la rondalla d'animals fins a la formulística. A més, torna a incidir, però ara de manera més específica, en el doble interès del segle Xıx per la rondalla: seguir les 
vel-leïtats del Romanticisme i centrar-se en allò intrínsec a la nació. Un material, aquest de les rondalles, que resulta difícil d'arreplegar per les inseguretats que crea en els informants pel públic que el pot escoltar.

Dues fites importants hi ha en aquest apartat: l'any I853 Manuel Milà i Fontanals és el primer a parlar de la rondalla en la premsa catalana, concretament en $\mathrm{La}$ Gaceta de Barcelona mitjançant I8 resums de rondalles, precedits d'una reflexió en què exalça la versió oral enfront a l'escrita; l'última referència és de Carles Besolí, de l'any I893, que publicà una versió de la rondalla «L'amor de les tres taronges» a La Rena(i)xensa. Per aquest marc és on es mou l'estudi present amb un resultat de I27 rondalles que l'autora ara distribueix entre «rondalles catalogades (85), rondalles no catalogades (35) i rondalles catalogades al web RondCat (7)» (p. 99) i que especifica en diferents taules, amb la peculiaritat de l'últim apartat, on la catalogació dels relats es fa a través de l'entitat «C—» en cas que hi haja dues versions d'un mateix argument. Aquest apartat finalitza amb una valoració conjunta en relació amb la tasca dels narradors i com del total de rondalles «només en 6 ocasions es dóna informació relacionada amb el narrador o la narradora en qüestió»(p.Io9); així com s'expressa la complexitat de fixar les rondalles, tema actualment resolt amb la fidelitat a la rondalla arreplegada, però que al segle xIx comportava parlar de diferents estils, en concret de tres: aquelles més fidels a l'oralitat i potser amb apunts sobre els informants; aquelles més literaturitzades per la mà del recol-lector, i aquelles incloses dins d'explicacions d'excursions o de la mateixa rondalla.

El segon apartat del tàndem que hem destacat ja hem comentat que és un tast de les rondalles arreplegades i, en concret, de la transcripció amb la corresponent versió original de «La merla» pel que fa a les rondalles catalogades, de «Lo bou d'or» dins de les no catalogades i d'«El criat llaminer» dins de les catalogades en el RondCat.

Així arribem al capítol que clou aquesta guia obligada dins dels estudis de literatura oral i, sobretot, de la rondalla amb un títol molt adient: «I rondalla contada, rondalla acabada». El seguit de conclusions comença amb el fet que l'estudi de la rondalla en la premsa catalana del xix confirma l'interès de diferents generacions d'erudits per aquest material, i dos noms destaquen com a nexe d'unió entre unes i altres: Manuel Milà i Fontanals i Francesc Maspons i Labrós, idea que referma l'estudi de Joan Prat. Aquest treball també ha possibilitat fer una llista de 5 revistes que durant aquesta època arrepleguen material rondallístic (per exemple, La Renaxensa) enfront de I3 que contenen altres materials propis de la literatura oral però no rondalles (per exemple, el Butlletí del Centre Excursionista de Catalunya). Així mateix, ha permès sumar, als 77 noms de folkloristes que arreplegava el RondCat, I6 més, i també ha permès classificar les rondalles amb un nou prisma depenent de l'estil de fixació dut a terme pels recol-lectors. Aquest estudi, ha suposat, a més, ampliar el corpus de rondalles ja conegut amb les I27 tractades, de les quals i9 són nous «tipus rondallístics en territori català -8 localitzats per primer vegada en l'àmbit dels Països Catalans i I I localitzats per primera vegada al Principat de Catalunya» (p. I5I). Així, mitjançant percentatges, l'autora classifica les I27 rondalles catalogades en els tres grups esmentats adés segons el seu subgènere, on la gran vencedora és la contarella seguida de la rondalla meravellosa. Però els percentatges també són emprats per fer una classificació segons les revistes on han estat publicades les rondalles, on la guanyadora és el Calendari 
Català «ja que s'hi ha localitzat 65 rondalles i contarelles transcrites, editades i comentades al corpus que representen el 5I\% del total» (p. I54). I s'hi afegeix una dada més: l'any en què més rondalles es publiquen en la premsa catalana del segle XIX va ser el I874.

Tota aquesta informació aportada i treballada al llarg del present estudi s'entén amb el gruix de referències bibliogràfiques que Mònica Sales aporta al final de l'obra i que referma la contundència d'aquest estudi, com ja dèiem, per al món folklòric i etnopoètic. 